\title{
The highly protective natural medical agents against COVID-19
}

\author{
Gokalp $F^{1}$, Sayin $\mathrm{K}^{2}$ \\ Kirikkale University, Faculty of Education, Department of Mathematics and Science Education, Science \\ Education, Yahsihan - Kirikkale, Turkey. akgokalp@gmail.com
}

\section{ABSTRACT}

OBJECTIVE: The studies to prevent the Corona virus, which is a huge epidemic nowadays and causes the death of many people, are of great importance. Drugs to be developed to prevent the proliferation and spread of it. The active substances of the drugs have been used to prevent the attack of the COVID-19. The natural phytochemicals obtained from the traditional medicine play a big role in the inhibition of functional structures in many harmful microscopic structures.

METHODS: The active role of the substances for protecting from the attack of COVID-19 have been calculated and determined by using docking.

RESULTS: It has been clarified that drug active substances inhibit COVID-19. The selected active ingredients seem to have considerable inhibition effects for COVID-19. Molecular mechanical Poisson-Boltzman (MM-PSBA) calculations were used to analyse the selected molecules.

CONCLUSION: This study is the first in terms of reducing the harmful effect of COVID-19 by providing effective results in a short time by guiding the experimental studies to reveal the inhibitory effect of COVID-19 (Tab. 3, Fig. 5, Ref. 25). Text in PDF www.elis.sk KEY WORDS: COVID-19, Carvacrol, docking Cucurbitacin-E and I.

\section{Introduction}

The published information related to the corona virus (1-10), which is an important epidemic disease, threatens the whole world by spreading rapidly. The discovery of drugs with an active ingredient necessary for the prevention of this virus epidemic as soon as possible is of great importance.

The traditional medicine has been used for the treatment of many diseases. Cucurbitacin E (11) and I, extracted from Ecballium elaterium in vitro have strong anticancer activities (12). The garlic prevents the coronavirus infection (13). Thymol and carvacrol have antiviral activity (14).

In this study; I tried to assess the inhibitory effect of the active substances in traditional medicinal plants as a prevention from the attack of COVID-19 by interacting with the active sites in it, comparing with the active compounds in latest medicine (15-18), using docking. The studies so far have been mostly related to the inhibition of the virus, but here the computational results will reveal its

${ }^{1}$ Kirikkale University, Faculty of Education, Department of Mathematics and Science Education, Science Education, Yahsihan-Kirikkale, Turkey, and ${ }^{2}$ Sivas Cumhuriyet University, Faculty of Science, Department of Chemistry, Sivas, Turkey

Address for correspondence: F. Gokalp, Kirikkale University, Faculty of Education, Department of Mathematics and Science Education, Science Education, 71450 Yahsihan - Kirikkale, Turkey.

Acknowledgment: Maestro program (Schrödinger Inc.) was supported by the Scientific Research Project Fund of Sivas Cumhuriyet University (CUBAP) under the project number RGD-020. effect on it. In addition, Molecular mechanical Poisson-Boltzman (MM-PSBA) calculations were made at $100 \mathrm{ps.}$

\section{Materials and methods}

The inhibitory effect of the active substances against COVID-19 has been investigated, using docking (19), which is an important part of theoretical calculation methods that prevents a loss of time and substance and provide fast and reliable results by directing experimental studies. 6LU7(20), is the main protease (Mpro) and the structure of PDB ID 7BV1 (21). Has been downloaded from PDB. In the docking calculations, Maestro program was used (22-24).

\section{Results and discussion}

Molecular placement calculations were made between the selected ligands and target proteins and possible inhibition points were determined. The receptor (7BV1)-ligand interaction docking results of the active compounds that can be used both as a drug and as a drug candidate against COVID-19 are given in the Table 1.

According to Table 1: When we compare the drugs according to the inhibition point selected in COVID-19, the order of effectiveness is from large to small; Lopinavir, Ritonavir, Remdesivir, Emtricitabine were identified as Thymol, Carvacrol, Cucurbitacin I, Cucurbitacin E, Allin and Allicin in drug candidates.

The receptor (6LU7)-ligand interaction docking results of the active compounds that can be used both as a drug and as a drug candidate against COVID-19 are given in the Table 2. 
Tab. 1. Receptor (7BV1)-ligand interaction docking scores of drugs used against COVID-19 and drug candidates that can be used.

\begin{tabular}{lccccc}
\hline Title & $\begin{array}{c}\text { Docking } \\
\text { score }\end{array}$ & Glide hbond & Glide evdw & Glide ecoul & $\begin{array}{c}\text { Glide rmsd } \\
\text { to input }\end{array}$ \\
\hline lopinavir_7BV1 & -5.384 & -0.586 & -46.243 & -8.373 & 161.075 \\
ritonavir_7BV1 & -4.730 & -0.386 & -38.165 & -10.455 & 159.462 \\
remdesivir_7BV1 & -4.599 & -0.405 & -42.780 & -11.500 & 163.552 \\
emtricitabine_7BV1 & -4.367 & -0.160 & -20.189 & -9.367 & 160.543 \\
thymol7BV1 & -4.303 & -0.306 & -16.295 & -3.690 & 161.169 \\
carvacrol_7BV1 & -4.292 & -0.233 & -15.634 & -4.403 & 161.665 \\
cucurbitacin_I_7BV1 & -3.702 & -0.242 & -28.655 & -11.957 & 165.253 \\
methylprednisolone_7BV1 & -3.533 & 0.000 & -21.646 & -9.139 & 164.110 \\
cucurbitacin_E_7BV1 & -3.006 & -0.065 & -29.071 & -9.255 & 164.791 \\
allin_7BV1 & -3.005 & -0.420 & -14.272 & -11.960 & 161.884 \\
allicin_7BV1 & -1.446 & -0.160 & -16.216 & -6.312 & 162.613 \\
\hline
\end{tabular}

Tab. 2. Receptor (6LU7)-ligand interaction docking scores of drugs and drug candidates that can be used against COVID-19.

\begin{tabular}{lcccccc}
\hline & $\begin{array}{c}\text { Docking } \\
\text { score }\end{array}$ & $\begin{array}{c}\text { Glide } \\
\text { hbond }\end{array}$ & $\begin{array}{c}\text { Glide } \\
\text { evdw }\end{array}$ & $\begin{array}{c}\text { Glide } \\
\text { ecoul }\end{array}$ & $\begin{array}{c}\text { Glide } \\
\text { energy }\end{array}$ & $\begin{array}{c}\text { Glide rmsd } \\
\text { to input }\end{array}$ \\
\hline carvacrol_6LU7 & -5.413 & 0.000 & -19.799 & -2.179 & -21.978 & 74.252 \\
cucurbitacin_E_6LU7 & -4.492 & 0.000 & -35.822 & -5.284 & -41.106 & 69.129 \\
allin_6LU7 & -4.345 & -0.608 & -20.613 & -7.585 & -28.198 & 72.387 \\
cucurbitacin_I_6LU7 & -4.059 & 0.000 & -38.292 & -3.401 & -41.693 & 69.076 \\
allicin_6LI7 & -3.361 & -0.320 & -21.118 & -6.514 & -27.632 & 74.369 \\
\hline
\end{tabular}

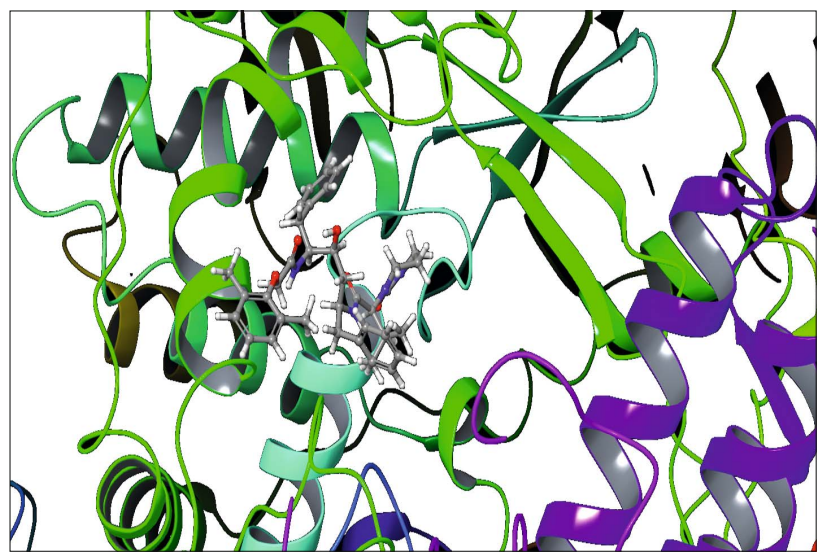

Fig. 1. Docking constructs for lopinavir and 7BV1 interaction.

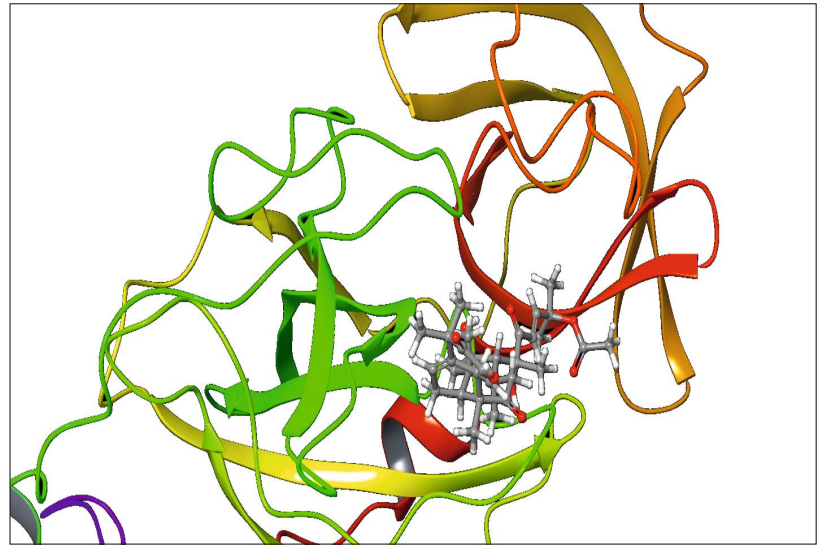

Fig. 2. Docking constructs for Cucurbitacin E and 6LU7 interaction.
As shown in Table 2: When we compare the drugs according to the selected inhibition point in COVID-19, the order of effectiveness is from large to small; Carvacrol, Cucurbitacin E, Allin, Cucurbitacin I, Allicin. The drug candidates were determined as Carvacrol, Cucurbitacin E, Allin, Cucurbitacin I and Allicin. The drugs that were effective in the previous table were found to have no interaction with 6LU7, so it is understood from the values in Table 2 that the inhibition effect of the drug candidates we selected here is quite good.

The most important criterion for determining the better drug candidate is the docking scores and energy criteria. This is because it is to pinpoint the point, where drug protein interactions are maximized. In Tables 1 and 2, the compounds with the best docking scores are shown in green.

The docking constructs for lopinavir and 7BV1 interaction are shown in Figure 1.

The docking constructs for Cucurbitacin E and 6LU7 interaction are shown in Figure 2.

Active site and ligand interactions of the proteins of interest were calculated using the Maestro 12.2 software program. For inhibitors, RdRp proteins with three colours red, blue and yellow means hydrogen bond acceptor, hydrogen bond. The electrostatic potential map of the ligand binding domain of 7BV1 and 6LU7 is shown in Figures 1 and 2.

The interaction scheme of Cucurbitacin E against 6LU7 is represented in Figure 3.

Tab. 3. Representation of DG of the binding free energy (kcal/mol) and standard deviation values of proteins and inhibitors.

\begin{tabular}{lcccccc}
\hline \multirow{2}{*}{ Time } & \multicolumn{2}{c}{ Lopinavir -7 BV1 } & & \multicolumn{2}{c}{ Cucurbitacin E -6 LU7 } \\
\cline { 2 - 3 } \cline { 5 - 6 } & Gibbs & Sapma & & Gibbs & Sapma \\
\hline 0 & -1751.43 & & & -2000.27 & \\
5 & -1666.14 & 264.1722 & & -2081.37 & 125.3038 \\
10 & -1725.91 & 401.978 & & -2116.07 & 175.1808 \\
15 & -1384.73 & 251.2816 & & -2204.27 & 280.9078 \\
20 & -1250.11 & 564.8606 & & -1991.27 & 174.4328 \\
25 & -1294.7 & 173.247 & & -2536.69 & 191.6915 \\
30 & -2074.17 & 346.0596 & & -2448.87 & 186.0501 \\
35 & -589.146 & 523.3729 & & -2319.18 & 213.9673 \\
40 & -481.659 & 354.695 & & -1728.31 & 201.4969 \\
45 & -907.828 & 259.2634 & & -2062.61 & 241.6059 \\
50 & -317.132 & 420.6072 & & -1694.83 & 199.3376 \\
55 & -1204.26 & 302.7578 & & -2387.21 & 310.1722 \\
60 & -1878.88 & 222.4171 & & -2254.69 & 156.1943 \\
65 & -1235.83 & 572.0848 & & -1844.45 & 109.0928 \\
70 & -2063.3 & 311.8518 & & -2280.45 & 146.5102 \\
75 & -1583.54 & 280.7978 & & -2147.26 & 206.302 \\
80 & -2491.27 & 575.2693 & & -1965.9 & 188.5194 \\
85 & -1525.56 & 369.3229 & & -2396.64 & 241.0785 \\
90 & -2173.78 & 203.6783 & & -2617.69 & 307.1099 \\
95 & -2301.85 & 308.4171 & & -1985.61 & 228.4795 \\
100 & -1729.09 & 161.6143 & & -1819.55 & 95.37519 \\
\hline
\end{tabular}




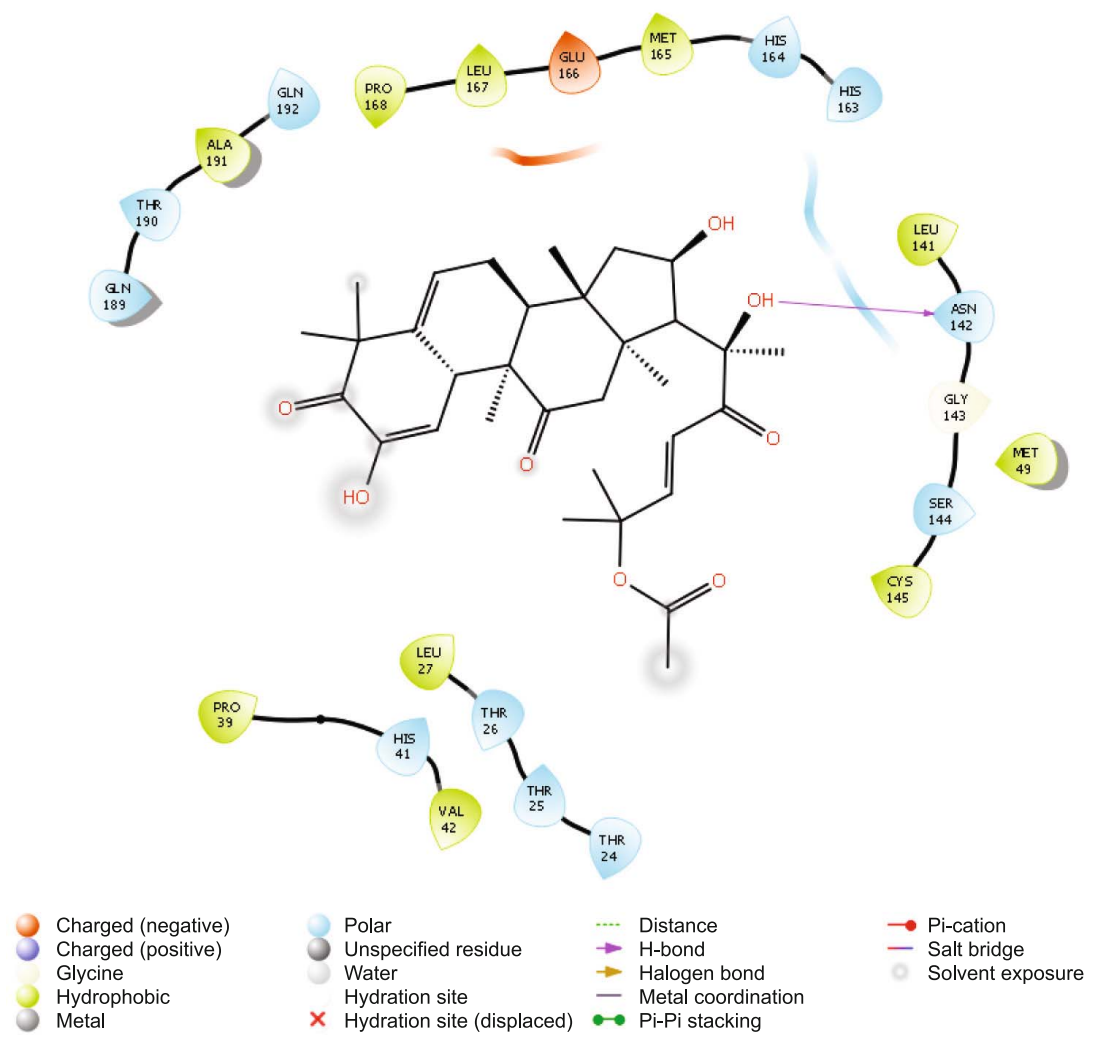

Fig. 3. The interaction scheme of Cucurbitacin E against 6LU7.

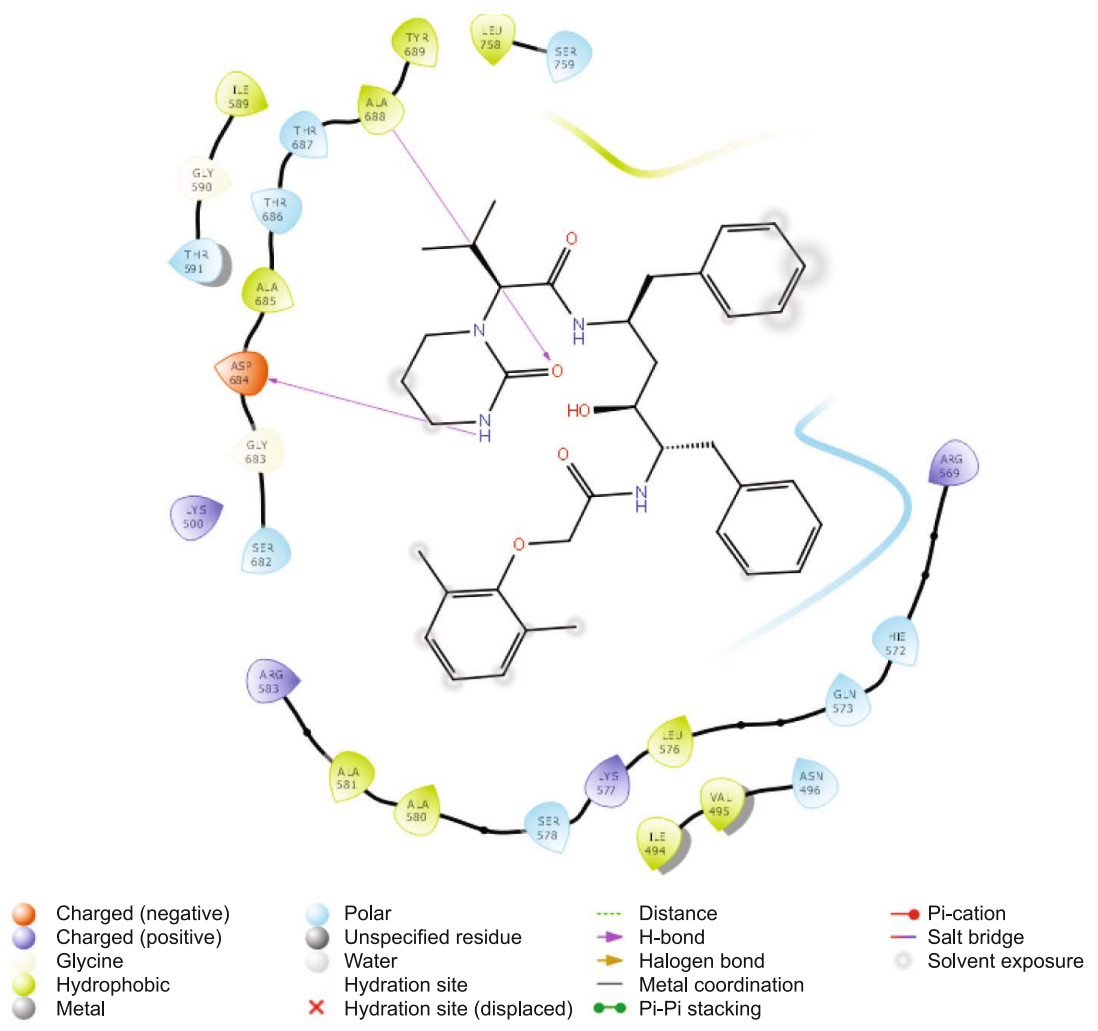

Fig. 4. The interaction scheme of Lopinavir against 7BV1. 


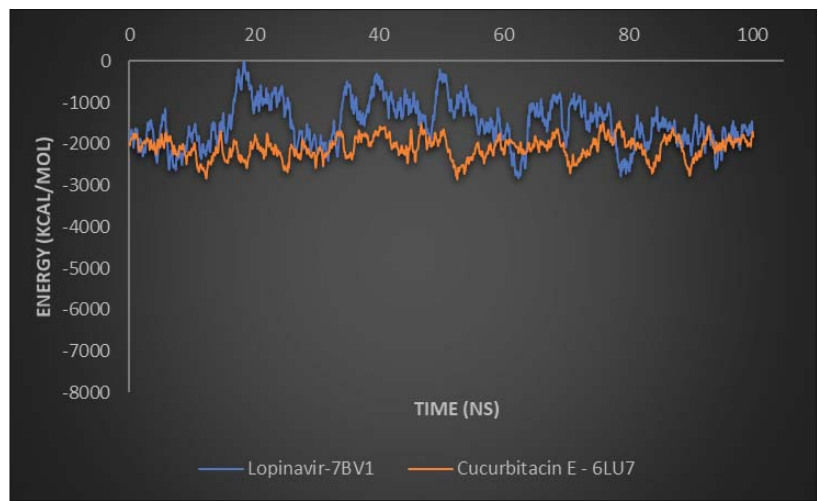

Fig. 5. Change of Gibbs free energy values of protein and inhibitors in every five ns intervals.

The interaction scheme of Lopinavir against 7BV1 is represented in Figure 4.

As can be seen in Figures 3 and 4, hydrogen bonding, hydrophobic, polar, charge (negative and positive) are important in these interactions in ligand-receptor interaction.

Docking analysis accepts the protein as a fixed structure, while the ligand is flexible. Molecular mechanics-Poisson-Boltzmann surface area (MM-PSBA) calculations should be done for a more detailed investigation, and in this calculation, the ligand and the protein are flexible and the solvent surrounds the whole structure. Gibbs free protein and ligand-protein energies for 6LU7 and 7BV1 are shown in Figure 5.

Lopinavir and the best performing drug candidate Cucurbitacin E inhibitory activities were compared to RNA-dependent RNA polymerase (RdRp) proteins. Supportive calculations were made with this comparison. Binding free energy changes and their deviations for every five ns intervals are given in Table 3 .

Molecular mechanics-Poisson-Boltzmann surface area (MMPBSA) calculations were made using the estimation of free energies of binding and are shown in the Table 3. As the result of the calculations. The mean values of Gibbs free energies were $-1729.09 \mathrm{kcal} / \mathrm{mol}$ for Lopinavir-7BV1; and for Cucurbitacin E $-6 \mathrm{LU} 7$ it is $-1819.55 \mathrm{kcal} / \mathrm{mol}$.

A large number of synthetic anti-viral drugs have been used to treat COVID-19 patients (25). Lopinavir/ritonavir can be recommended to relatively high-risk groups of COVID-19 pneumonia (15). Low-dose intravenous methylprednisolone has showed a substantial improvement with a marked reduction of pulmonary exudative lesions (16) Remdesivir is a highly effective drug for controlling COVID-19 infection in vitro (17). Opinavir/ritonavir combined with abidol showed anti-viral effects for COVID-19 (18).

According to these results, the free energy changes Cucurbitacin E-6LU7 exhibits good properties. We can conclude through the MM-PSBA that the best drug candidate for the COVID-19 virus is Cucurbitacin E.

\section{Conclusion}

Cucurbitacin E and I are the essential ingredients in Ecballium elaterium and is the most important basic component of Ecballium elaterium. It has been determined with the computational results that the active substances in the selected plants are docked and the virus is prevented from entering the cell. As the result, we can conclude that they might be used most effectively against COVID-19.

\section{References}

1. Seah I, Su X, Lingam G. Revisiting the dangers of the coronavirus in the ophthalmology practice. Nature.com, 2020.

2. Du Toit A. Outbreak of a novel coronavirus. Nature Reviews Microbiology, 2020.

3. Zhou P, Yang XL, Wang XG, Hu B, Zhang L, Zhang W et al. A pneumonia outbreak associated with a new coronavirus of probable bat origin Nature, 2020.

4. Wu F, Zhao S, Yu B, Chen YM, Wang W, Song ZG et al. A new coronavirus associated with human respiratory disease in China, Nature, 2020.

5. Nkengasong J. China's response to a novel coronavirus stands in stark contrast to the 2002 SARS outbreak response Nature Medicine, 2020.

6. Wang M, Cao R, Zhang L, Yang X, Liu J, Xu M, Shi Z et al. Remdesivir and chloroquine effectively inhibit the recently emerged novel coronavirus (2019-nCoV) in vitro. Cell Research, 2020.

7. Huang C, Wang Y, Li X, Ren L, Zhao J, Hu Y, Zhang L et al. Clinical features of patients infected with 2019 novel coronavirus in Wuhan, China - The Lancet, 2020.

8. Yu F, Du L, Ojcius DM, Pan C, Jiang S. Measures for diagnosing and treating infections by a novel coronavirus responsible for a pneumonia outbreak originating in Wuhan, China, Microbes and Infection, 2020

9. Chen H, Du Q.Potential Natural Compounds for Preventing 2019-nCoV Infection, bigcanoe.themountainsvoice.com, 2020.

10. Lagi F, Pollini S, Zammarchi L. Clinical role of viral identification by a polymerase chain reaction-based diagnostic panel in adults hospitalized with community-acquired pneumonia. Internal and Emergency Medicine, 2020.

11. Hamidi M, Ghasemi S, Bavafa Bighdilou B, Eghbali Koohi D, Yousefbeyk F. Evaluation of Antioxidant, Antibacterial and Cytotoxic Activity of Methanol Extract from Leaves and Fruits of Iranian Squirting Cucumber (Ecballium elaterium (L.) A. Rich). Res J Pharmacognosy 2020; 7 (1): 23-29.

12. Morales-Vela K, Pérez-Sánchez FC, Padron JM, Márquez-Fernández O. Antiproliferative Activity of Cucurbitaceae Species Extracts from Southeast of Mexico. Preprints 2019; 2019080127. DOI: 10.20944/preprints201908.0127.v1.

13. Shankar A, Saini D, Roy S, Mosavi Jarrahi A, Chakraborty A, Bharti S, Taghizadeh-Hesary F. Cancer Care Delivery Challenges Amidst Coronavirus Disease - 19 (COVID-19) Outbreak: Specific Precautions for Cancer Patients and Cancer Care Providers to Prevent Spread. Asian Pacific J Cancer Prevention 2020; 21 (3): 569-573. DOI: 10.31557/ APJCP.2020.21.3.569. 
14. Konuk HB, Ergüden B. Phenolic -OH group is crucial for the antifungal activity of terpenoids via disruption of cell membrane integrity. Folia Microbiol 2020.

15. Lim J, Jeon S, Shin HY, Kim MJ, Seong YM, Lee WJ, Choe KW, Kang YM, Lee B, Park SJ. Case of the Index Patient Who Caused Tertiary Transmission of Coronavirus Disease 2019 in Korea: the Application of Lopinavir/Ritonavir for the Treatment of COVID-19 Pneumonia Monitored by Quantitative RT-PCR. J Korean Med Sci 2020; 35 (6): e79.

16. Xiang-Hong $\mathbf{J}$ et al. COVID-19 in a patient with chronic lymphocytic leukaemia. Lancet Haematol 2020; 7-4: e351-e352.

17. Chang Y, Tung Y, Lee K, Chen T, Hsiao Y, Chang H, Hsieh T, Su C, Wang S, Yu J, Shih S, Lin Y, Lin Y, Tu YE, Hsu C, Juan H, Tung C, Chen C. Potential Therapeutic Agents for COVID-19 Based on the Analysis of Protease and RNA Polymerase Docking. Preprints 2020; 2020020242.

18. Xu K, Cai H, Shen Y et al. [Management of corona virus disease-19 (COVID-19): the Zhejiang experience]. Zhejiang da xue xue bao. Yi xue ban $=\mathrm{J}$ Zhejiang Univ Med Sci 2020; 49 (1): 0.

19. Siti K, Hendra K, Rizki A, Suhartati S, Soetjipto S. Potential Inhibitor of COVID-19 Main Protease (Mpro) from Several Medicinal Plant Compounds by Molecular Docking Study, 2020. DOI: 10.20944/ preprints202003.0226.v1.
20. Khaerunnisa S, Kurniawan H, Awaluddin R, Suhartati S, Soetjipto S. Potential Inhibitor of COVID-19 Main Protease (Mpro) From Several Medicinal Plant Compounds by Molecular Docking Study. Preprints 2020; 2020030226. DOI: 10.20944/preprints202003.0226.v1. https://www. rcsb.org/.

21. Yin W, Mao C, Luan X, Shen DD, Shen Q, Su H, Wang X, Zhou F, Zhao W, Gao M, Chang S, Xie YC, Tian G, Jiang HW, Tao SC, Shen J, Jiang Y, Jiang H, Xu Y, Zhang S, Zhang Y, Xu HE. Structural basis for inhibition of the RNA-dependent RNA polymerase from SARS-CoV-2 by remdesivir. Science 2020; 368 (6498): 1499-1504. DOI: 10.1126/science.abc 1560 .

22. Schrodinger. (2019a). Schrodinger Release 2019-4: LigPrep. Schrodinger, LLC.

23. Schrodinger. (2019b). Schrodinger Release 2019-4: Maestro. Schrodinger, LLC.

24. Schrodinger. (2020). Schrodinger Release 2020-1: QikProp. Schrodinger, LLC.

25. Rahman MT. Potential benefits of combination of Nigella sativa and Zn supplements to treat COVID-19. J Herb Med 2020; 23: 100382.

Received February 9, 2021. Accepted March 25, 2021. 